UDC 811.111

DOI: $10.17223 / 24109266 / 8 / 6$

\title{
RETRANSLATION OF HUMOUR AS A POSITIVE INTERCULTURAL COMMUNICATION STRATEGY
}

\author{
O.A. Leontovich \\ Volgograd State Socio-Pedagogical University (Volgograd, Russian Federation) \\ E-mail: olgaleo@list.ru \\ Acknowledgements \\ The research is supported by grant № 15-04-00500 \\ of the Russian Foundation for Humanities.
}

\begin{abstract}
Humorous discourse is a positive communication strategy, which contributes to the success of intercultural encounters. On the other hand, wrong interpretation of humorous culture-specific meanings can be a cause of communication failures. The present paper analyses five translations of I. Ilf and E. Petrov's books The Twelve Chairs and The Golden Calf from Russian into English. The study shows that the key factors which influence the construction of cultural meanings include: background knowledge, presuppositions, imagery, evaluation, emotional perception, cultural context, connection with precedent concepts and texts, and intertextuality. The treatment of cultural meanings also depends on the historical period when the translation is done and the political views of the translator.

Keywords: positive communication strategy; humorous discourse; retranslation of culture-specific meanings; connotation; intertextuality; intercultural communication.
\end{abstract}

\section{Introduction}

Society generally views positive communication as a desirable form of relationship which contributes to mutual understanding and effective human interaction. It is based on positive emotions and is satisfying for all the parties involved [1].

Humour is among the leading communication strategies "enhancing feelings of being understood, a vital component of interpersonal need fulfilment" [2]. Whereas it is almost universally seen as a positive factor improving intercultural communication, its erroneous interpretation or discrepancy of cultural perceptions can sometimes hinder understanding - as Virginia Woolfe put it, Humour is the first of the gifts to perish in a foreign tongue. We might conclude therefore that competent interpretation and translation of humour become vital components of effective intercultural interaction.

Humour attains its aim when it becomes shared meaning between interlocutors. On the other hand, meanings seen as funny are relative, as they are socially, psychologically, culturally and situationally conditioned. In in- 
tercultural settings humour can either blossom or, on the contrary, "perish" due to the divergence of different semiotic systems, incongruity between norms of behaviour, or lack of background knowledge.

The present study is based on the analysis of five translations of Ilya Ilf and Evgeniy Petrov's works The Twelve Chairs (1928) and The Golden Calf (1931) seen by many Russians as the funniest books of all times. It is only natural to admit that it is impossible to carry out their exhaustive analysis in one short paper. The study pursues the following tasks: 1) to discuss the notion of "cultural meaning"; 2) to investigate the genesis of cultural meanings and the regularities of their construction as positive communication phenomena; 3 ) to identify various strategies of retranslating humorous cultural meanings for a foreign audience; 4) to analyse associated problems and ways to overcome them.

\section{Discussion}

We distinguish between Meaning 1 (Rus. znacheniye) and Meaning 2 (Rus. smysl), which can be with a certain deal of approximation rendered, correspondingly, as dictionary meaning and meanining-in-use. Meaning 1 (znacheniye) is independent of context, non-interactive and static, whereas Meaning 2 (smysl) is, in its turn, context-dependent, interactive and dynamic. If Meaning 1 is precontextual and forms the basis of mutual understanding between interlocutors, Meaning 2 is co-created by the interlocutors in a context [3].

Embarking on the study of cultural meanings, it is appropriate to recollect D.A. Leontiev's remark that the correlation of smysl and znacheniye reflects capabilities and limits of human communication and understanding [4: 375]. According to Y.A. Sorokin's definition, "znacheniye is conceived as the essence of an object correlated with a particular sign; smysl - as its interpretation by a certain number of recipients on the basis of their collective and/or personal experience" [5:59]. From this point of view, translation is a product of triple interpretation - on the part of the author, translator and reader. The interpretation of cultural meanings presupposes not only the knowledge of factual information about a particular culture, but also the ability to extract in-depth senses expressed by linguistic units in a context. Those meanings interweave, interact with one another, and it is only possible to adequately construe them by taking into account the complexity of their interplay.

One of the popular and effective present-day interpretative approaches to the study of texts is constructivism, which views culture as a transcedent historical process of meaning creation providing the interpreting individuals with ready-made meanings and symbols. In the process of socialization "individual systems of constructs are smoothly coordinated with the system of 
sociocultural meanings" $[6: 61]$. Constructivists believe that reality cannot be regarded as fully independent of the way a person conceptualizes it; "perception depends on coding the world into iconic signs that can re-present it within our mind" [7: 11].

A. Cruse suggests that meanings "emerge in actual use as a result of various processes of construal (mental processes of meaning construction)". He claims that a permanent property of every word is a mapping onto a body of conceptual content (purport) which acts as "an essential part of the raw material for the construal processes" [8:262]. This perspective is concordant with the point of view expressed by A.V. Smirnov who treats meaning not as a fixed content but only as its potential implemented in the process itself. He defines meaning (smysl) as a continuum with "a regression to infinity" [9: 34$35,99]$. This echoes L.S. Vygotsky's idea that " $<\ldots>$ the presence of a second, inner aspect of speech behind the words, the independence of the grammar of the mind, the syntax of word meanings make us see not a once given, immobile and constant relationship between the semantic and phonetic aspects of speech in a simple utterance, but a movement, a transition from the syntax of meanings to the word syntax, the modification of the meaning structure implemented in words" [10: 298].

Where does the cultural component come from, what is its genesis? It can be either integrated in the meaning or induced by the inner or outer context as a result of inference. The factors which influence meaning construction from the point of view of its cultural specifics include: 1) background knowledge; 2) presuppositions; 3) imagery; 4) evaluation; 5) emotional perception; 6) cultural context; 7) connection with precedent concepts and texts; and 8) intertextuality.

A fruitful approach to the analysis of cultural meanings and modes of their retranslation was introduced by U. Eco who wrote about nuclear content which includes minimal concepts, i.e. elementary requirements allowing to recognize an object or understand a construct - and the corresponding linguistic expression [11: 103]. Similarly, D.A. Leontiev argues that in the language of psychological mechanisms, meaning construction can be seen as the process of disseminating meaning from the leading, "nuclear" semantic structures to particular, peripheral, derivative ones in concrete situations of an unfolding action [4: 255].

The form of verbalization of cultural meanings allows us to classify them as a) explicit where the nationally specific component is included in the nucleus, and b) implicit where it exits on the periphery (see the works by O.A. Leontovich about the typology of cultural meanings: [3, 12]). Explicit cultural meanings participate in the creation of the key content of a literary work, whereas implicit meanings are present as a sort of halo, an undecoded latent constituent which gives it an ethnospecific colouring but is not always comprehended and processed by the translator and the reader. 
I.V. Popchenko believes that the nucleus of a comedic worldview is universal and includes phenomena of international humour comprehensible for representatives of different cultures; the middle part (between the nucleus and the periphery) includes culture-specific representations of humour, whereas the periphery is based on the individual comedic worldview of the author of a corresponding text [13:3-4].

Given the last statement, it is quite a challenge to draw demarcation lines between those constituents because, as L.S. Vygotsky puts it, the enrichment of the word with intellectual and affective senses which it absorbs from the whole context constitutes the main law of the dynamics of meanings [10: 333]. One might also speculate about the double-layer/multilayer character of meanings, their complex constellation, qualitative change of meanings in the process of their realization in the context, etc.

Text comprehension presupposes the matching of the author's and reader's meanings. The author's meaning unfolds from its original conception towards the mode of its verbal expression, its realization in the text; it is further perceived by the reader and decoded into the language of thought. These processes inevitably presuppose partial loss and/or modification of meaning, firstly, because of the difficulty of accurately expressing thoughts by means of words, and secondly, because the addressees impose their own interpretation on what has been said. The depth of comprehension depends on the cognitive base shared by the communicators (in our case - writer and reader) which can differ depending on the historical period, age, gender, education, life experience, etc.

Communication in an intercultural setting is complicated by the presence of translators (retranslators of culture) serving as intermediaries. They inevitably have to deal with the problem of translatability. According to D. Chandler, linguistic universalists claim that practically everything can be translated; linguistic relativists, in their turn, believe that the transference of meanings between languages is very problematic and at times impossible; they suggest that even the reformulation of a thought within one language is fraught with distortions and losses [14].

We proceed from a compromise according to which part of the cultural meanings is inevitably lost in the process of translation, but the main content can be verbally expressed. The question now arises: is the understanding of all cultural meanings critical for the comprehension of a literary work and its positive perception, in particular a humorous one? The overarching aim here is not to discuss its in-depth analysis by literature specialists who strive to understand the meaning of each word, but ordinary readership for the sake of enjoyment. Which cultural meanings are a must for retranslation and which can be rephrased or altogether omitted because of the difficulty or, moreover, impossibility of their verbal expression? 
P.V. Donets suggests that it is necessary to discern between discrete (i.e. clearly distinguishable, visually imaginable) and non-discrete (fuzzy, vague, abstract) meanings. From his point of view, "the former ones can be identified by means of contrastive comparison of the systems of cultural meanings, whereas the latter require complex analytical procedures" [15: 187].

It means that in order to comprehend and translate cultural meanings one has to tackle two major problems: 1) understand the components of cultural meanings through their verbalisation; 2) grasp the regularities of their combination into a single whole in the text. If we agree with A.V. Smirnov that different cultures use different logics of meaning formation, one has to admit that, in addition to a certain amount of specific information about a tradition or culture required for the comprehension of a certain content, one also needs to understand the logical procedure forming this content [9: 46-92].

Among other things, the translation of a literary work implies a mediated transference of cultural meanings from one culture to another. The translator's aim here is to interpret and present the information in a form providing for its maximum comprehension by the target audience. In an intercultural context we actually deal with double translation: from a culture to a retranslator and from a retranslator to the target audience. It also includes the adaptation of meanings to the scope of cultural knowledge of the target audience, i.e. representatives of a different culture.

Translation of a humorous text is a double challenge: it is necessary not only to make it comprehensible but also funny and enjoyable. The danger is that "humour can be dissected, as a frog can, but the thing dies in the process" (E.B. White).

Let us take a look at the problems and their solution on the example of the translations of Ilya If and Evgeny Petrov's works.

Challenges start with the translation of the book titles themselves. If J. Richardson (Ilf, Petrov, 1965) keeps the original name of the book The Twelve Chairs, E. Mill and D. Mudie (Ilf, Petrov, 1930) change the title supplementing it with an allusion to William Shakespeare's play well known to the English-speaking readers: Diamonds To Sit On. A Russian Comedy of Errors. This attempt at creativity probably brings the book closer to the target audience but is somewhat too far-fetched and evokes meanings nonexistent in the original.

K. Gurevich and H. Anderson (Ilf, Petrov, 2009) translate the sequel's title as The Golden Calf, whereas both Ch. Malamuth (Ilf, Petrov, 1932) and A.O. Fisher (Ilf, Petrov, 2009) go for The Little Golden Calf trying to make up for the absence of a diminutive suffix in English corresponding to the Russian telyonok. Both titles can be justified, but I find the first variant preferable, as, in my opinion, "little" here is excessive.

In this and other cases translators have to make conscious decisions about the accuracy, credibility, and comprehensibility of their representation 
of cultural meanings. By accuracy I mean the expression of cultural information in the form most faithful to the original and the source culture. An obvious illustration of this is the simple transcription or transliteration of proper names, e.g.: Ostap Bender, Ippolit Matveyevich Vorobyaninov, Kondratyevna, Pasha Emilevich, Shura Balaganov, Panikovsky.

If the accurate representation of the information or phenomenon is impossible, the information must at least be credible, i.e. approximated to the depicted cultural reality. In particular, a translator can use English analogies of Russian realities, if it does not incur any serious loss of meaning. Since intercultural communication presupposes two sets of knowledge - of people belonging to two different cultures, the translator takes into account the cultural competence of the target audience and uses adaptation, or adjustment of cultural meanings to their cognitive base.

For example, Russian names are quite lengthy and difficult for the perception by English-speaking readers, therefore translators sometimes partially adapt them, i.e.: Father Fiodor - Father Theodore; Katerina Alexandrovna - Catherine Alexandrovna; Klavdia Ivanovna - Claudia Ivanovna; Andrei Ivanovich - Andrew Ivanovich. Female surnames are often translated without the ending - $a$ (Russian marker of feminine gender): Madame Gritsatsuyev, Ellochka Shukin, Kokushkin.

An effective way of preserving the humorous effect produced by the "speaking names" is their partial translation: thus, fire chief Nasosov (from Rus. nasos - pump) acquires the surname Pumpoff.

Various kinds of connotations play a special role in humorous discourse. In connection with this, Russian diminutives become a real torture for translators. Some attempt to express their meaning with the help of little: zerkal'naia polochka - a little mirrored shelf, shkafchik - a little cabinet, chemodanishko - a little suitcase, or other adjectives: etazherochki - low bookshelves. Others ignore them altogether: chemodanisko - a plain-looking suitcase, blondinchik - the fair-haired young man.

For the understanding of nuances of meaning it is necessary not only to know but also feel the connotations expressed by particular suffixes. For a non-Russian speaker they are a meaningless set of sounds and are lost on them altogether. E.g. a foreign reader is unaware that the surname Vorobyaninov is marked by a certain degree of aristocratism, unlike, for example, a more common surname Treukhov. The surname Trubetskoi-Lapis sounds rather pretentious. The names Nikesha and Vladya clearly characterise their owners as infantile blockheads. The simple English transcription of the names Pasha Emilevich and Pashka does not allow an English-speaking reader to appreciate the attitude, evaluation, social acceptability, or the appropriateness of their use in different contexts.

It is necessary to point out that translators should also keep in mind the degree of relevance of information. Even though we can regret that Eng- 
lish does not accurately express the connotations of such words as tishaishiy (translated as extremely quiet) or upoitel'niy (delightful), this will not seriously affect the general perception of the book. On the other hand, the nickname Kisa given to Vorobyaninov (one of the main characters of The Twelve Chairs) by Ostap Bender and rendered in English as Pussy, can acquire undesirable and even obscene connotations in an English context.

More nuances of meaning are verbalized with the help of synonyms. I cannot stand the temptation of including here Richardson's translation of the famous episode from The Twelve Chairs marked by a skilful use of a whole range of verbs meaning "to die" (an undertaker's professional jargon):

"So the old lady's passed away. Old ladies pass away... or they depart this life. It depends who she is. Yours, for instance, was small and plump, so she passed away. But if it's one who's a bit bigger and thinner, then they say she has departed this life..."

"What do you mean 'they say'? Who says?"

"We say. The undertakers. Now you, for instance. You're distinguished-lookin' and tall, though a bit on the thin side. If you should die, God forbid, they'll say you popped off. But a tradesman, who belonged to the former merchants' guild, would breathe his last. And if it's someone of lower status, say a caretaker, or a peasant, we say he has croaked or gone west. But when the high-ups die, say a railway conductor or someone in administration, they say he has kicked the bucket. They say: 'You know our boss has kicked the bucket, don 't you?',"

Shocked by this curious classification of human mortality, Ippolit Matveyevich asked: "And what will the undertakers say about you when you die?"

"I'm small fry. They'll say, 'Bezenchuk's gone', and nothin' more". And then he added grimly: "It's not possible for me to pop off or kick the bucket; I'm too small',

The translators of Ilf and Petrov's books make ample use of proper names and allusions to the cultures of other countries from the original text, e.g.: Hamlet, Prince of Denmark, Columbus Theatre, Madam Butterfly, League of Nations, Chamberlain, Fujiyama, etc. These names act as a certain starting point for the "internationalization" of the text, they place the action into a broader context comprehensible for representatives of other cultural communities: Her voice was so strong and fruity that it might well have been envied by Richard the Lionheart $<\ldots>$; How talented I was in my time in the role of Hamlet!; William Shakespeare's vocabulary has been estimated by the experts at twelve thousand words (Richardson); Or take this one, the European pedestrian movement's very own last of the Mohicans; "No, this is no Rio de Janeiro" [16, 17].

The cultural meanings expressed by such proper names as Zhukovsky, Milyukov, Budyonny, Gerasim and Mumu, Dolgoruki, Yusupov, Pugachov, Ogonyok, Pravda will hardly be comprehended by an English-speaking 
reader, therefore in some cases the translators specifies them, e.g.: poet Zhukovsky, or, similarily, when quoting Pushkin: <..>P Pushkin's poem: "There he stood, full of great thoughts, on the bank...". It is difficult to imagine that an average reader (not a language or literature specialist) will be looking up the meaning of each culturally-specific term or passage in dictionaries or encyclopaedias.

Unfortunately, even though the translations under analysis to a certain extent retain the vivacity and cheerfulness of the original, they still lose the irresistible wit and proverbial character of the key phrases which are so highly appreciated by the fans of Ilf and Petrov's works:

"Does the Nymph, durn it, really give good service?"

My coffins are like gherkins, specially selected for people who know a good coffin.

A passionate woman is a poet's dream.

Do-Us-the-Honour Funeral Home.

"Things are moving, gentlemen of the jury!"

I am commanding the parade!

Great importance is attached to the first and last phrases of each book. P. Janse discusses different translations of the opening phrase of The Golden Calf: "Pedestrians should be loved" (Malamuth); "Pedestrians just need to be loved" (Fisher) and "You have to be nice to pedestrians" (Gurevich and Anderson): "Maybe there is something to be said for 'need to' instead of 'should', but I do not like the 'just' at all. It introduces an emotional note, which may be present in the original, but only in an implicit way. The Russian sentence is delightfully laconic and a perfect opening of a novel. The translation by Mrs. Fischer is too awkward $<\ldots$. . Gurevich and Anderson (2009) have 'You have to be nice to pedestrians'. Hm. 'To be nice to' is not the same as 'to love', is it?" [18].

A lot can also be said about the closing phrase of The Golden Calf. P. Janse writes that Anne Fisher's 'I'll have to get re-trained as an apartment building supervisor' "is an exact representation of the original content, but really..." He also indicates that the English or American 'concierge' is not exactly the same as the Russian 'upravdom', "but is the difference so great that this colourless, awkward three-word translation is necessary? This is the final sentence of Ilf and Petrov's finest novel! How can you do this to the reader?" In his opinion, Gurevich and Anderson's 'I'll have to go into apartment management instead' "sounds a little, but not much, better" [Ibid.].

Other situations fraught with communicative failures are those which require the comprehension and visualization of phenomena and artefacts well known to representatives of Russian culture (at least at the time when the book was written). Some Soviet realities are expressed by means of word-for-word translation: communal-service workers' local committee; the regional-executive-committee car Gos. No. 1; women's work division; the 
Boulevard of Young Talents; the Leningrad Lumber Trust; the cooperative cafeteria 'The Former Stomach's Friend', etc. The notion itself can be vague for an English-speaking reader, but the use of the terms, at times quite exotic, gives the text a certain culture-specific flavour.

Important for the interpretation of literary works are precedent texts. One example is the reference to the untraditional staging of Gogol's "Marriage" described in The Twelve Chairs. Its comic character is comprehensible only to those who are familiar with this classical play, its content, characters and the peculiar treatment of the original utterances.

Numerous songs used in the texts are much more meaningful for Russians than for foreign readers because the former know the melodies and numerous meaningful associations that are perceived as part and parcel of their native culture. For a foreign reader such songs as: Haa-aapy daa-aays... (Byvali dni vesiolye, The Apple (Yablochko)) and others are practically meaningless and do not create a mood intended by the author.

The painting The Bolsheviks Answer Chamberlain devised by Ostap Bender is an allusion to Ilya Repin's famous painting Zaporozhtsy are writing a letter to the Turkish Sultan. The inability to visualise it makes impossible the further appreciation of humorous meanings, such as: "Comrade Kalinin in a fur cap and white cape" and "Comrade Chicherin stripped to the waist".

Translators follow different paths trying to fill in the gaps in the cultural competence of their readership. Fisher provides 300 endnotes to The Little Golden Calf (2009), which, on the one hand, contribute to the understanding of the book, but, on the other, steal some of the humour.

When things become far too complicated some translators omit challenging passages altogether. As Fisher indicates, Ch. Malamuth "arbitrarily cut many of the segments that give the novel its narrative charm and topicality: completely absent are the typewriter with the Turkish accent, the rebusmaker Sinitsky, the detailed descriptions of Khvorobyov's Soviet dreams, the scene of Ostap Bender dancing the tango with Koreyko's case file in the empty Bureau of Horn and Hoof Procurement, and the wonderful passage on the differences between the big world and the little world in Chapter Nine. Malamuth seems to have decided that these scenes were too silly or too culture-specific, and left them out" [16: 25-26].

Gurevich and Anderson replace the phrase 'Down with Khovanshhina!' ('Doloy Khovanshhinu!' - a reference to Musorgsky's opera) with 'Down with the Queen of Spades!' "believing that the English public is better acquainted with Tchaikovsky's music" (Janse).

In her introduction to The Little Golden Calf, A. Fisher makes a number of very interesting observations about the degree to which a translation depends on the historical period when it is made and on the political standpoint of the translator. Malamuth, she says, "had personal experience of the 
Russia of Ilf and Petrov's novels, $<\ldots>$ while Richardson translated both novels during the surge of interest in early Russian literature encouraged by the Thaw $(<\ldots>$ he published his translation in 1961). According to her, "Malamuth also took occasional liberties with the text. For example, $<\ldots>$ Funt converts to Judaism and has to wear his "Passover" trousers, not his Easter trousers, every day. Malamuth also adds several sardonic references to the Five-Year Plan and socialist competition (no doubt reflecting his own recent disillusionment with Soviet rhetoric) and inserts a silly slogan of his own ("Electricity + Soap = Revolution's Hope") to the list of slogans offered to the Antelope-Gnu in Chapter Six". Richardson, on the other hand, entirely removes all the direct references to God - "perhaps in a bow to Cold War stereotypes of "godless Communists"" [16: 25].

This can partially account for the differences in the representation of cultural meanings by different translators [19-21].

\section{Conclusions}

1. The study shows that humorous discourse is a positive communication strategy which contributes to the success of intercultural encounters. On the other hand, wrong interpretation of humorous culture-specific meanings can be a cause of communication failures.

2. The key factors which influence the construction of cultural meanings include: background knowledge, presuppositions, imagery, evaluation, emotional perception, cultural context, connection with precedent concepts and texts, intertextuality, etc. The comprehension of humorous culture-specific meanings can be tentatively subdivided into two constituents: a) the understanding of the components of meaning; b) the understanding of the logic of their combination into a single whole in the communication process.

3. Retranslation of culture-specific meanings, i.e., their verbalization and adaptation for the target audience, is one of the greatest challenged facing a translator of a literary work. The factors which can violate the comprehension of a text retranslated from one culture to another include verbal mistakes, imprecise connotations, insufficient background information, discrepancy between form and meaning, violation of context distribution of meanings, disparity in value orientations and their manifestation in communicative behaviour. The treatment of cultural meanings also depends on the historical period when the translation is done and the political views of a translator.

\section{References}

1. Leontovich, O.A. (2014). Positive Communication: Definition and Constituent Features. Vestnik of Volgograd State University. Series 2. 5 (24). pp. 123-125. 
2. Bodie, G.D. (2014). Listening as Positive Communication. The Positive Side of Interpersonal Communication. Socha, Thomas J. and Pitts, Margaret J. (eds.) Available at: https://www.academia.edu/669027/Listening_as_Positive_Communication (accessed: 23.11.2014).

3. Leontovich, O.A. (2010). Typological classification of cultural meanings. New Trends in Lexicography: Ways of Registrating and Describing Lexis. Cambridge: Cambridge Scholars Publishing. pp. 23-35.

4. Leontiev, D.A. (2003). Psychology of meaning: nature, construction and dynamics of meaning reality. $2^{\text {nd }}$ ed. Moscow: Smysl.

5. Sorokin, Yu.A. (1985). Psycholinguistic aspects of the study of the text. Moscow: Nauka.

6. Makarov, M.L. (2003). Foundations of discourse theory. Moscow: Gnozis.

7. Nichols, B. (1981). Ideology and the Image: Social Representation in the Cinema and Other Media. Bloomington, IN: Indiana University Press.

8. Cruse, A. (2004). Meaning in Language. An Introduction to Semantics and Pragmatics. Oxford University Press.

9. Smirnov, A.V. (2001). Logic of meaning. Moscow: Jazyki slavjanskoj kul'tury.

10. Vygotskij, L.S. (2007 [1931]). Thinking and speech. Moscow: Labirint.

11. Eco, U. (2006). To say almost the same. Experiences in Translation. St. Petersburg: Symposium.

12. Leontovich, O.A. (2008b). Typology of cultural meanings. Language, culture, communication: collection of papers in honour of prof. S.G. Ter-Minasova, Moscow State University. Moscow: Gnozis. pp. 502-510.

13. Popchenko, I.V. (2005). Comedic worldview as a fragment of the emotional worlview: on the material of I. Ilf's and E. Petrov's texts. Doct. dis. abstract. Volgograd: Volgograd State Pedagogical University.

14. Chandler, D. (2005). Semiotics for Beginners. 2005. Available at: http://www.aber.ac.uk/media/Documents/S4B/semiotic.html (accessed: 04.05.2016).

15. Donets, P.N. (2001). Foundations of general theory of intercultural communication. Har'kov: Shtrih.

16. Fisher, A.O. (2009). Foreword. In: The Little Golden Calf by Ilya Ilf and Evgeny Petrov (trans. by Anne O. Fisher). Montpelier, VT: Russian Life Books.

17. Interviews and Personalities (2011). In: Translation and Interpreting by Anne Fisher. Available at: http://www.sras.org/anne_fisher_translation_interpreting (accessed: 03.05.2016).

18. Janse, P. (2016). Translation Issues. Available at: http://pjanse.home.xs4all.nl/IlfPetrov/translation.html (accessed: 22.05.2016).

19. Emerson, C. Professional Reviews. Available at: http://www.russianlife.com/books/fiction/the-little-golden-calf/ (accessed: 22.05.2016).

20. Leontovich, O.A. (2008a). The problem of retranslation and adaptation of cultural meanings. Vestnik MGU. 2. pp. 18-24.

21. Razumovskaja, V.A. and Czan Godun (2009). Humorous discourse as a translation problem: on the material of the translations if I. Ilf's and E. Petrov's novel "The Twelve Chairs". Vestnik Irkutskogo gosudarstvennogo lingvisticheskogo universiteta. 2009. 4 (8). pp. 87-93.

\section{Translations of I. Ilf and E. Petrov's books}

Ilf I., Petrov E. (1930). Diamonds to Sit On. A Russian Comedy of Errors (trans. Elizabeth Mill и Doris Mudie). London.

Ilf I., Petrov E. (1932). The Little Golden Calf (authorized trans. by Charles Malamuth; with an introduction by Anatole Lunacharsky). New York: Farrar \& Rinehart, inc. 
Ilf I., Petrov E. (1965). The Twelve Chairs (trans. John Richardson; introduction by Maurice Friedberg). London: F. Muller.

Ilf, I., Petrov, E. (2009). The Golden Calf (trans. Konstantin Gurevich and Helen Anderson). Rochester, NY: Open Letter.

Ilf, I., Petrov, E. (2009). The Little Golden Calf (trans. by Anne O. Fisher). Montpelier, VT: Russian Life Books, 2009.

Resived 02.09.2016.

\section{Information about the author}

Leontovich Olga - Professor, Head of Department of Intercultural Communication and Translation Volgograd State Socio-Pedagogical University (Volgograd, Russian Federation).

E-mail: olgaleo@list.ru 